\title{
Initiating e-Participation Through a Knowledge Working Network
}

\author{
Louise Rasmussen, Elisabeth Davenport, Keith Horton \\ International Teledemocracy Centre \& School of Computing \\ Napier University, Edinburgh EH10 5DT, UK. \\ e.davenport@ napier.ac.uk
}

\begin{abstract}
The authors present a study of e-participation within a public sector agency (PSA), where a number of knowledge management initiatives have been introduced since the inception of the UK 'Modernising government' programme of 1999. The agency has attempted to set up an internal participatory infrastructure to manage 'knowledge' across the network of local enterprise companies through which agency policy is operationalised. The trajectory of knowledge management versions in PSA is thus a rich indicator of power-plays in the organisation, and the discussion uses discourse analysis to explore the document base (field notes, textual data paper and electronic, formal and informal) that was produced at three historical moments. The aim is to understand patterns of participation and resistance in a number of einitiatives within the agency. The authors highlight the choices relating to the stimulating, fostering, encouraging, embracing, contesting, ignoring, and perhaps rejecting of this e-participation project. Such insights are important to our understanding of the influences upon e-governmental initiatives, an area of UK public spending that is littered with IT project failures.
\end{abstract}

\section{Introduction}

The concept of E-participation is discussed more in terms of the citizen-government interface than in terms of internal modernisation of government. A paradigmatic OECD report on e-democracy for example, defines e-participation as: 'A relation based on partnership with government in which citizens actively engage in defining the process and content of decision-making' [1 p. 12,2 passim] The paper presents a study of e-participation within a public sector agency (PSA), where a number of knowledge management initiatives have been introduced since the inception of the UK 'Modernising government' programme of 1999. The study involves participant observation, and the researcher has worked in the organisation for three years, since her matriculation as a doctoral student. The case is an interesting one: the agency is a brokerage of sorts, whose mission is to engage small local enterprises, or facilitate 
the participation of SMEs with government policy to regenerate Scotland's industry. Much of the facilitation depends on ICTs. But in order to ensure that such facilitation is streamlined across regions, the agency has attempted to set up an internal participatory infrastructure to manage 'knowledge' across a network of local enterprise companies through which agency policy is operationalised. The paper explores the provenance of this infrastructure, explains the theoretical perspective and approach, and presents an extract of the case study as an example of what the approach may deliver. Some observations are discussed in the final part of the paper.

Historical analysis of knowledge management (KM) in PSA reveals a number of different initiatives, or 'versions' that emanate from the centre (HQ), that can be mapped on a timeline and plotted in terms of key events (such as seminars by influential consultants and gurus), or shifts in personnel (particularly at senior management level). The versions can be linked to competing KM discourses, championed by different senior agency officers at different times. These discourses problematise organisational knowledge in different ways, and the 'solutions' that they entail provide different groups in the agency with an opportunity to bid for resources. The resource implications of a KM discourse may persuade bystanders to participate in a give initiative, as it is in their interest to do so; where they have no interest, they will take part minimally or not at all. The allegiance of local groups is not guaranteed, and the number of adherents that a given KM initiative attracts may thus be an indication of the power of its proponents.

The trajectory of KM versions in PSA is thus a rich indicator of power-plays in the organisation, and the researcher uses discourse analysis to explore the document base (field notes, textual data paper and electronic, formal and informal) that was produced in KM activity at three historical moments. The aim is to understand patterns of participation and resistance in a number of e-initiatives (albeit KM initiatives) within the agency. But it is hoped that this understanding may also provide insight into ways of researching participation and resistance at other levels of societal interaction. A comparable stud of a public agency was undertaken by Carter and Scarbrough in 2001, one of several that constitute a Foucauldian research agenda in Information Systems Research recently reviewed by Willcocks [3].

\section{Background}

The research organisation is a QUANGO (quasi-autonomous non-governmental organisation) or Executive NDPB (non-departmental public body), and its remit is to facilitate economic development in Scotland. The organisation was set up under the Enterprise and New Towns (Scotland) Act 1990. It consists of a headquarters and twelve distributed subsidiaries. Collectively, the headquarters and subsidiaries are called a 'network'. Following a business transformation programme, knowledge practitioners' were recruited to form a knowledge network (referred to as the 'network' in the study) that would embed KM into the business. In mid-2002 the organisation proceeded to recruit a number of knowledge practitioners across the 
organisation to embed $\mathrm{KM}$ tools and techniques into the business. This panorganisation distributed knowledge network consists of a team located at HQ and a distributed team of Knowledge Analysts (KA), each situated within a subsidiary. The research student was recruited in August 2003 to undertake the role of Knowledge Analyst in one of the subsidiaries. A vacancy arose in another subsidiary in August 2004 that included research and evaluation work, as well as a reduced KA remit. This the research student accepted on a 4-day week basis. Two days a week would be spent on research and evaluation, and the other two days on KA related-work. This move afforded the research student the opportunity to study another case in a different subsidiary. The overall study includes three case studies of the panorganisational knowledge network, the local subsidiary the research student was an employee of between October 2003 and October 2004, and the local subsidiary within which the research student is now situated.

\section{The theoretical perspective}

An initial approach to the study took a dialogical perspective, an approach that Schultze and Stabell [4] suggest is neglected in the KM literature. The dialogical perspective draws on the pioneering work of Bakhtin and Volosinov [5] who explain discourse in terms of continuous struggle between the different voices ('heteroglossia') that populate the world. Schultze and Stabell [4] suggest that dialogical discourse is similar to critical discourse as it too "is interested in social conflict and the role of knowledge in the exercise of power and control" [ $4 \mathrm{p}$. 560]. It differs in the emphasis it places on the mutual shaping and construction of phenomena [4]. It also takes a neutral political stance that doesn't view power as being exerted but exercised [4]. The dialogical approach offers little methodological guidance, and the researcher turned to the work of Michel Foucault who offers a powerful and demanding framework for exploring organizational discourse. This resonates with Foucault's concept of knowledge and power as being mutually constituted, and his view of power as being exercised. What Foucault doesn't do is provide methodological guidelines to undertake research in this area $[6,7,8]$. However, there is a growing interest in examining discourses that describe organisational change and discourse analysis is the method frequently employed to do so $[9,10]$.

At this point it may be useful to clarify what is meant by 'discourse' in this study. The researcher has worked with definitions from Foucault, a "general domain of statements", an "individualised group of statements", and "regulated practice that accounts for a number of statements" (Foucault cited by [11 p. 123]; from Fairclough "ways of representing the world" [11 p. 124], and from Introna "as a particular way of talking, of making statements, about the world" [12 p. 237]. So, in an abstract sense, discourse is understood in the study as different ways of viewing material, mental and social worlds. A discourse analytic framework was derived for the study on the basis of a literature review, a core source for which was Schulze and Leidner's [13] paper, "Studying Knowledge Management in Information Systems Research: Discourses and Theoretical Assumptions". Five main discourse elements 
were identified: 'value', 'psychology', 'object', 'practice' and 'structure'. These are briefly summarized below.

The 'value' discourse contends that knowledge is a valuable economic resource that must be managed. The basic assumption is that value is derived from ensuring and sustaining a competitive advantage. In order to do this, the resource-based theory of the firm advocates that resources should be valuable, rare, and not easily be imitated or substituted [14]. Codified knowledge assets can be commercially protected through patents, copyrights or trademarks they become valuable through exploitation. Tacit knowledge, though unique is difficult to define and describe, and as a result difficult to quantify, though methods are emerging for this. The second element of the framework, 'psychology' discourse, suggests that KM success depends on appropriate behaviours, norms and beliefs. The objective is to habitualise and institutionalise 'good' behaviours, norms and values to ensure KM success. Examples are building social capital through social networks; helping leaders "walk the talk", in other words, "do what they say they will do"; implementing reward and recognition programmes; and lastly "creating new heroes" by making individuals" good behaviours and achievements public [15 p. 177]. But, often the onus lies on management to exhibit the right behaviours, say the right things, do what they say they will do, motivate and reward staff.

The 'object' discourse is based on the assumption that knowledge can be reified, affording organisations the opportunity to 'manage' the knowledge creation process [16]. This discourse encompasses a technocratic approach that primarily concentrates on the use of ICTs to connect people with people and people with information. Consequently, information communication technologies (ICTs) such as intranets, databases, discussion groups, and even decision-making support and e-learning software are dominant themes in discourse.

From the 'practice' discourse view, where knowledge is viewed as socially constructed, context-specific, and rooted in action, organisations are turning their attention to the 'management' of knowledge through people, utilising narrative techniques and community networking models, commonly known as Communities of Practice (CoPs). A CoP model consists of a community of individuals, working within a shared domain, who have a vested interest in working together to enhance their domain [17]. Consequently, the community model is hailed as the ideal platform to share tacit-made-explicit knowledge, utilise technical tacit knowledge, and construct shared identities, beliefs, and values that contribute to the right organisational culture. The 'structure' discourse is concerned with organizational networks, both invisible and visible. Teigland [18] distinguishes between 'emergent' (invisible social networks) and 'formal' or visible networks of practice, Formal, in this sense, differs from the definition of formal organisation structure that delineates positions of authority, function or geography depicted in the typical organisation chart. The distinction between emergent and formal networks is important, as visible networks can potentially be cultivated or managed. Some organisations, including the research organisation, take a more formal approach to $\mathrm{CoP}$ development. By bringing individuals together to bridge intra- and inter-organisation boundaries (formal networks), the hope is that patterns of relationships will mirror those 
naturally occurring networks (emergent) based on friendship and trust. Cultivating a CoP takes time and money, and typically an organisation that invests in CoPs will want to see or extract some benefit. Thus, it is plausible that people developing a $\mathrm{CoP}$ are bound by management to make CoPs 'work' and hence, tread a very fine line between fostering and managing a CoP. What is sometimes forgotten is that an organisation will include both types of structural forms, those that are mandated by the organisation chart and informal networks (both formal and emergent), and that tensions arise in the struggles for resources, authority and recognition between these two structures.

The five discourse elements have been used to analyse the field data gathered in the three case studies. As high level units of analysis, they provide a starting point for unraveling the often complicated struggles that characterize KM implementation, and gaining insight into patterns of participation. The discourse framework is by no means definitive, but it reflects the researcher's 'feel' as an insider for the research organisation. As we can see in the case study, the elements overlap - structure, value and practice converge in the case of CoPs.

\section{The method}

Yin [19] describes a case study as "one of several ways of doing social science research" (pg 1). He posits that the case study is a useful strategy when: "how" or "why" questions are posed; the researcher has little influence over events; or when studying contemporary phenomena in a real-life (organisational) context. Furthermore, a case study is, according to Creswell "an exploration of a 'bounded system' or a case (or multiple cases) over time through detailed, in-depth data collection involving multiple sources of information rich in context" [20 p. 61]. A case study has been chosen for a number of reasons. The researcher's workplace satisfies these criteria.

\subsection{The position of the researcher}

In qualitative research there are a number of roles researchers can assume in their quest to obtain data. These range from conducting research in complete secrecy to 'participant observation', where an employee might become a researcher [20]. Participant observation does not infer direct observation as the employee researcher can only be in a specific place at a specific time as and when the job demands this. Also, Czarniawska [21] points out that important events do not necessarily happen at the point of observation, but at other times and in different places. In addition, she states that researchers cannot determine that an event is significant when it takes place. Instead, important events are constructed post-hoc (ibid). Czarniawska introduces the term 'observant participant', a method whereby company employees were asked to note their observations, thus contributing to the research study $[21 \mathrm{p}$. 785]. In this research endeavour, the term extends to what was gleaned in interaction with colleagues. Although there has been no conscious effort to ask them to record their observations, their observations are gathered as and when the research student 
is able to converse with them. These observations, recorded as field notes, are only one of the multiple sources of information collection; other data includes emails and documents. This assemblage constitutes an archive that is addressed in a genealogical analysis $[7,8]$.

The research organisation is sponsoring this research and the research student has made overt the fact that research is being conducted in the domain of KM and is concerned with the KM and its implementation in the organisation. The sponsor has not asked for specific details of how the research is being conducted and the data analysis methods have not been explicitly discussed. Sensing the research organisations' reluctance to allow invasive questioning, it was decided to assemble the data described above using unobtrusive methods. So field notes have been captured where possible and textual data such as emails and documents collected. An important consideration is to remain non-judgemental about specific individuals and groups.

The research student is not doing action research as she is not in a position to exert any great influence within the organisation at HQ level, local level or within the distributed knowledge network. This is primarily due to the fact that the researcher does not play a central role in decision-making or strategic planning in either of these locales. Decisions are either taken on collective basis or by management, and similarly the same individuals propose any interventions. In addition, the distributed nature of the knowledge network the research student is situated in limits opportunities for regular interaction. Although the designated KA role implies that the KA be a 'change agent' that diagnoses problems, suggests a solution, and helps implement the solution, this has not happened in practice. The role of the $\mathrm{KA}$ is supportive and though KAs may contribute in ways that ensure that certain problems or issues are resolved, this is not through not through personal diagnoses of the problem situation.

To say that this study does not involve action research is not to neutralize the presence of the researcher within the discourse, or knowledge network, that is explored. The researcher's role is inextricably coupled with the rhetorics and structures that condition activity in PSA, what Carter and Scarbrough describe as the 'structural repertoire' of the organization [16 p. 211]. (We return to this point inour later discussion of the Foucauldian subject). Following Foucault [8], who wrestled with the problem the ambivalent status of the researcher or 'archaeologist' as his methodological approach evolved, the researcher does not wish to clarify what KM is and should be, or whether knowledge can be managed and is managed correctly, but to embrace the ambiguities of KM to track their trajectory in an organisational setting. The study is not concerned with motivations or why certain individuals seek to dominate or their strategy for doing so. Rather, the focus is on ways in which discursive formations emerge, and this research endeavour is being promoted internally as an opportunity to discover how a discourse is formed within the organisation.

The case study that is presented below is concerned with patterns of participation as the knowledge management concept evolved, and thus with the political trajectory of a distributed knowledge network. In the organisation, Knowledge Management 
$(\mathrm{KM})$ and Knowledge Working (KW), have specific connotations and both terms are used in the study. In addition, there are a number of abbreviations in this draft case study and these are listed in Table 1 below.

Table1 Case Study Abbreviations

$\begin{array}{ll}\text { BT } & \text { Business Transformation } \\ \text { CoP } & \text { Community of Practice } \\ \text { HQ } & \text { Headquarters } \\ \text { KA } & \text { Knowledge Analyst } \\ \text { KM } & \text { Knowledge Management } \\ \text { KW } & \text { Knowledge Working } \\ \text { NDPB } & \text { Non-Departmental Public Body } \\ \text { QUANGO } & \text { Quasi-Autonomous Non-Governmental Organisation }\end{array}$

\section{The case study: constructing a knowledge infrastructure, 1999- 2004}

We start the story in April 1999, when the network approved a 'Knowledge Web' project. Initially this was a business re-engineering project, which later became a fully-fledged business transformation (BT) project. The BT project vision was "to help [the organisation] become a leading economic development agency, and more open, accessible and accountable through the use and communication of knowledge" (Briefing, Oct 1999). This project consisted of two main elements: firstly addressing the culture and behaviour in how knowledge is shared, learned, applied and interpreted; and secondly the processes and technology (ibid). Ten BT workstreams were identified to consider a change agenda, one of which included 'Knowledge' This mentioned the recruitment of 'Special-K People' who would have specialist knowledge skills to manage the core knowledge system; provide professional support, advice and training in managing knowledge; and finally, monitor and maintain best practice in KM. It was anticipated that these Special-K people would be able to assist, acquire and store knowledge. Exactly how these individuals would be deployed, and KM operationalised, was a matter for continuing debate.

At this stage, the K-discourses at work were primarily the 'psychology' and 'object' discourses. An example of the mapping of knowledge working principles and proposed activities to discourse views can be seen in Table 2 below. Table 2 sets out some examples from the HQ view of the future of knowledge working across the organization, as demonstrated in documentation collated (esp. Knowledge Architecture, Dec 2002), shown here in terms of the focus for a series of principles that were set out, the associated means of achieving them, and some implications for a future design stage. The fifth column in the table shows a mapping of these areas to discourse views, as outlined above, derived from a preliminary analysis of a data 'snapshot' for the 3-month period October to December 2002.

In June 2000 the role of 'Knowledge Analyst' was invented, and in July 2002 'Special-K People' or 'Knowledge Working Specialists' as they became known, were recruited into a new Knowledge Working (KW) team within the KM 
directorate (How $\mathrm{KM}$ is applied at XX, 2003). A 'future state operating model' or human resource allocation model was proposed in 2002, which dictated that each subsidiary had to recruit a Knowledge Analyst (KA). So what does this structure mean in practice? The headquarter KW team are formally depicted on HQ's organisational chart, whereas the KA's are a member of a team within the subsidiary. Typically, they are included in a team that deals with ' $\mathrm{KM}$ ' activities such as strategy, finance, research and evaluation. As was mentioned previously, the term ' $\mathrm{KM}$ ' has specific connotations in the organisation. It is associated primarily with a "value' discourse, and with quantitative measures and targets including financial number crunching. Whilst the KW HQ team are responsible for developing and implementing tools and techniques ('object' discourse) for KW (How KM is applied, 2003), the KA's are responsible for identifying and interpreting the knowledge needs of staff ('psychology' discourse). Utilising a participation framework called the 'Knowledge Needs Route Map' (developed with the help of an IBM consultant between June and November 2003) and KW toolkit, KA's recommend and implement appropriate KW tools and solutions. The toolkit includes 'tacit' and 'explicit' tools. The primary 'tacit' tool is the community of practice, and the 'explicit' tool the intranet. Both are integral in breaking down organisational boundaries to encourage network communication and collaboration - 'practice, 'object' and 'psychology discourses converge here.

Towards the end of 2003 the KW team, KA's, their line managers, and other interested parties were taken through a two-day workshop and emerged as a 'CoP'. The KA's are an integral piece of the KW puzzle. Without them, HQ can't identify which local subsidiary priorities are important, recommend $\mathrm{KW}$ solutions, and apply them in the business. In isolation, the KW team and $\mathrm{KA}$ 's operate in their own separate 'boxes'; the KW team at head office level, and each KA in their local subsidiary. As a KW CoP, the KW team and KA's operate both vertically (within HQ and subsidiary) and horizontally (across geographical boundaries). The KW CoP members are geographically distributed and operate in a virtual manner using technologies such as the intranet, telephone, and discussion groups. However, it is not pure 'virtual' entity as some members are co-located; others do meet on occasion and all members meet twice a year: a further discourse comes into play, 'structure'.

But the 'value' discourse retains its strength. Up until July 2005, on a yearly basis each subsidiary submitted a strategy to head office to procure funding to undertake economic development activities in their local area. Their measure of performance and subsequent funding is dependant on meeting a set of quantitative targets agreed by the government. The subsidiaries view these HQ imposed compulsory changes as detrimental; they erode their autonomy, represent a loss of innovation, and require the subsidiaries to achieve more with fewer resources. As the imposed KA post represents a potential loss of an operational member of staff, the subsidiaries were cautious in employing people whose role cannot demonstrate clear value-added benefits to their organisations. But, they were required to adhere to the new staffing structure imposed by $\mathrm{HQ}$.

Because of the fluid nature of the KA job it was virtually impossible for KA's to identify a foreword schedule of work, and hence, articulate the potential benefit the 
organisation can derive from their interventions. Consequently, it was very difficult to attribute any direct value to $\mathrm{KW}$ and the reason why $\mathrm{KW}$ is perceived to be a 'pink and fluffy' concept by adherents of the 'value' discourse. In August 2003, ten months after the KA's were first introduced, a Change and Communications (C\&C) Manager was brought in to provide strategic direction for the KA role (meeting, Aug 2003). In an attempt to paint a rosy picture to ensure the subsidiaries devote more time to $\mathrm{KW}$, he classifies all the work the KA's do as KA work, and a very positive message is conveyed, but the reach and impact in the business is diminished. In June 2004, the KW CoP core group leader, also a KA, expressed reservations about the classification: "the role [the C\&C Manager] created and sold or miss-sold is now our problem" (conversation, June 2004). Reservations are also evident in quotes from emails in June 2004 prior to a scheduled meeting with a Senior Director of Operations (SDO) nominated as the KW CoP sponsor.

\section{Discussion}

The Throughout the KA period (2000-2004) there is considerable tension between $\mathrm{HQ}$ "them" priorities and local subsidiary "us" priorities. This is articulated in conflicting and shifting K-discourses that are characteristic of a dialogic process at work. Some subsidiaries did not consider CoPs to be a local initiative or priority. CoPs may derive benefit for the organisation, but they were labour intensive, and only include a select few people in the local subsidiary. The time devoted to CoPs minimised time that could be spent on local issues, perhaps not even related to $\mathrm{KW}$, which would have a far greater reach or impact on the business. Perhaps as a result of emphasising the importance of 'local demand' the KW Director, C\&C Manager, and $\mathrm{KA} \mathrm{Co-ordinator} \mathrm{mentioned} \mathrm{that} \mathrm{the} \mathrm{KW}$ strategy needed refreshing. The primary focus of these contests is the figure of the Knowledge Analyst, the organizational role occupied by the researcher, who can be seen as a Foucauldian subject - the product of a set of discourses formed round knowledge management. Because the KA role was initially directed from $\mathrm{HQ}$, and KA's asked to undertake work without prior agreement with local line management, KAs are a material and bodily focus of organizational tensions. KA spirits were flagging as one KA attests: "Am just trying to get on with things and stay as positive as possible but continue to feel that being in a "network" post in [subsidiary] will never work (as demonstrated by my recent performance grading)." (email, June 2004). The KA's often questioned why they were not structured as a shared service team as they were promoted by some of their seniors as one.

\subsection{The Knowledge Analyst as Foucauldian subject}

The construction of the 'subject' of the Knowledge Analyst can be mapped in parallel with the tracking of different $\mathrm{K}$-discourses. Just as the discourse of the clinic implicates a number of subjects (the figure or subject of the patient is an example whose treatment is contested in a dialogic process that sustains the domain), the discourse of KM in PSA has produced the figure of the KA, whose treatment is also 
contested, a contest that sustains the KM programme in the organization, as there is always something to be acted upon. The KAs questioned the KW network structure on many occasions. As a result of the BT project numerous network policies and procedures were being implemented across the board. More often than not HQ developed these with little input from the subsidiaries, the operations arm of the business. Many of the local problems faced involved an issue with a network directive that couldn't be solved locally but at a network level. As such, KA's found it difficult to intervene at a local level. Some KA's questioned whether local issues would be better addressed at a $\mathrm{CoP}$ level. This, it was felt, would be a better forum for $\mathrm{KW}$ interventions. But, as mentioned above, $\mathrm{CoPs}$ were not considered a local priority and the KA's were not perceived to be delivering locally if they focused on a network initiative. When the future-state operating model was first introduced, it was conceived that the KA's would operate as a shared service (discussion, July 2004). But, for some reason, when this operating model was drawn up a KA was to be situated in each subsidiary. It is possible, that at that stage, HQ thought that the subsidiaries wouldn't want another HQ team imposed on them. This was the reason given when discussing the group structure on numerous occasions. The KA Coordinator, a member of the BT workstream, mentioned that they were not consulted when HQ were considering this model. Six months later when HQ recruited for a $\mathrm{KW}$ team, it became apparent that the structure was an inhibitor and this was raised as a concern. However, political ramifications were cited as the reason why management would not, or could not, challenge this model. In May 2004, following a CoP meeting, the KW AQ Director capitulated and asked the C\&C Manager and $\mathrm{KA} \mathrm{Co-Coordinator} \mathrm{to} \mathrm{investigate} \mathrm{the} \mathrm{structure} \mathrm{and} \mathrm{draft} \mathrm{a} \mathrm{management} \mathrm{paper.} \mathrm{But,}$ it wasn't made clear to them what would happen to this paper, if anything. Yet another set of options were proposed at a KA meeting in August 2004. One, the structure remains as is and subsidiaries would be asked to devote more time to $\mathrm{KW}$. Two, a central shared service team would be recruited with less KA's. Three, one KA would service two subsidiaries but would be managed locally. This would require network-wide consultation and a survey would be drafted and sent out to $\mathrm{HQ}$ Executive Board, HQ KW team; subsidiary CEO's, KA Director, KA Line Manager, and KA's.

\section{Conclusion}

To conclude, the research findings presented are preliminary, with analysis of data continuing, and with the researcher still participating in the organisation. At first glance the unraveling of the knowledge working trajectory demonstrates the complexity of attempts in this case to encourage e-participation in this public sector organization - a key aspect in the UK Government's attempts to 'modernise work'. However, the consideration of discourse views alerts us to the many ways in which this discourse can be interpreted. One of the features of this case is the way in which the HQ inspired of e-participation through knowledge working is to be implemented 
upon (sic) local, semi-autonomous, structural units. From what we see in this case study so far, this would appear to reflect a phenomenon noted elsewhere in public sector IT initiatives, namely discourse dissonance [22], consequences of which include elitism (and inertia), resistance, and speciation (where there are variants in practice). To this we may add contention as a possible consequence, where the discourse, in this instance relating to e-participation through knowledge working, becomes a locus for social actors [23] to contest the exercise of power. Thus, concentrating upon variations in the nature of discourse over time (for what will be several years for the organization reported upon in this case extract) at the HQ level as well as at the local 'business unit' level, should enable a detailed assessment of the life of the e-participation/knowledge working initiative. As part of this, developments in the views of what 'e-participation' and 'knowledge working' are become more visible, as do choices relating to the stimulating, fostering, encouraging, embracing, contesting, ignoring, and perhaps rejecting of this project. Such insights are important to our understanding of the influences upon egovernmental initiatives, an area of UK public spending that is littered with IT project failures [24].

\section{References}

1. OECD, Citizens as partners: information, consultation and public participation in policymaking (OECD, Paris, 2001).

2. OECD, Promises and problems on e-democracy: challenges of online citizen engagement. (OECD, Paris, 2003).

3. L. P. Wilicocks, Michel Foucault in the social study of ICTs: critique and reappraisal. Department of Information Systems Working Paper Series, 138 (London School of Economics and Political Science, London, 2006).

4. U. Schultze and C. Stabell, Knowing What You Don't Know? Discourses and Contradictions in KM Research, Journal of Management Studies 41(4), 449-573 (2004).

5. J. Maybin, Language Struggle and Voice: The Bahktin \& Volosinov Writings, in: Discourse Theory and Practice: A reader, edited by $\mathrm{M}$. Wetherell et al,. (Sage, London, 2001), pp. 64-71.

6. M. Foucault, The Archaeology of Knowledge and the discourse on language (A. M. Sheridan Smith trans.) (Pantheon Books, New York, 1970).

7. M. Foucault, Discipline and Punish: The Birth of the Prison (Vintage, New York, 1979).

8. H. Dreyfus and P. Rabinow, Michel Foucault: beyond Structualism and Hermeneutics (The University of Chicago Press, Chicago, 1982), pp. 208-226. 
9. B. Flyvbjerg, Making Social Science Matter (Cambridge University Press, Cambridge, England, 2001).

10. D. Grant, G. Michelson et al., Guest editorial: discourse and organizational change. Journal of Organizational Change Management 18(1), 6-15 (2005).

11. N. Fairclough, Analysing Discourse. Textual analysis for social research (Routledge, London, 2003).

12. L. D. Introna, Disciplining Information Systems: Truth and its Regimes, European Journal of Information Systems 12, 235-240 (2003).

13. U. Schultze and D. Leidner, Studying KM in Information Systems Research: Discourses and Theoretical Assumptions, MIS Quarterly 20(3), 213-242 (2002).

14. G.von Krogh, J. Roos et al., Knowing in Firms. Understanding, Managing and Measuring Knowledge. (Sage Publications Ltd, London, 1998).

15. M. C. Rumizen, The Complete Idiot's Guide to Knowledge Management (CWL Publishing Enterprises, Indianapolis, 2002).

16. C. Carter and H. Scarborough, Towards a second generation of KM? The people management challenge, Education and Trainiung 43(4/5), 215-224 (2001).

17. E. Wenger, R. McDermott, et al., A Guide to Managing Knowledge. Cultivating Communities of Practice (Harvard Business School Press, Boston, MA, (2002).

18. R. Teigland, Knowledge Networking: Structure and Performance in Networks of Practice (Gotab, Stockholm, Sweden, (2003).

19. R. K. Yin, Case Study Research Design and Methods (Sage Publications Ltd., London, 2003).

20. J. W. Creswell, Qualitative Inquiry and Research Design: Choosing Among Five Traditions (Sage Publications Ltd., London, 1998).

21. B. Czarniawska, On Time, Space, and Action Nets, Organization 11(6), 773-791 (2004).

22. E. Davenport and $\mathrm{K}$. Horton A social-shaping perspective on an eGovernmental system(ic) failure, in: Lecture Notes in Computer Science volume 3183: Electronic Government: Third International Conference, EGOV'04, Zaragoza, Spain, August 30September 3, 2004 (Springer, Berlin/ Heidelberg, 2004), pp. 186-193.

23. R. Lamb and R. Kling, Reconceptualizing users as social actors in information systems research. MIS Quartery 27(2), 197-235 (2003).

24. The Economist, A harsh master: Public sector IT projects (12 March,2005), p.38. 


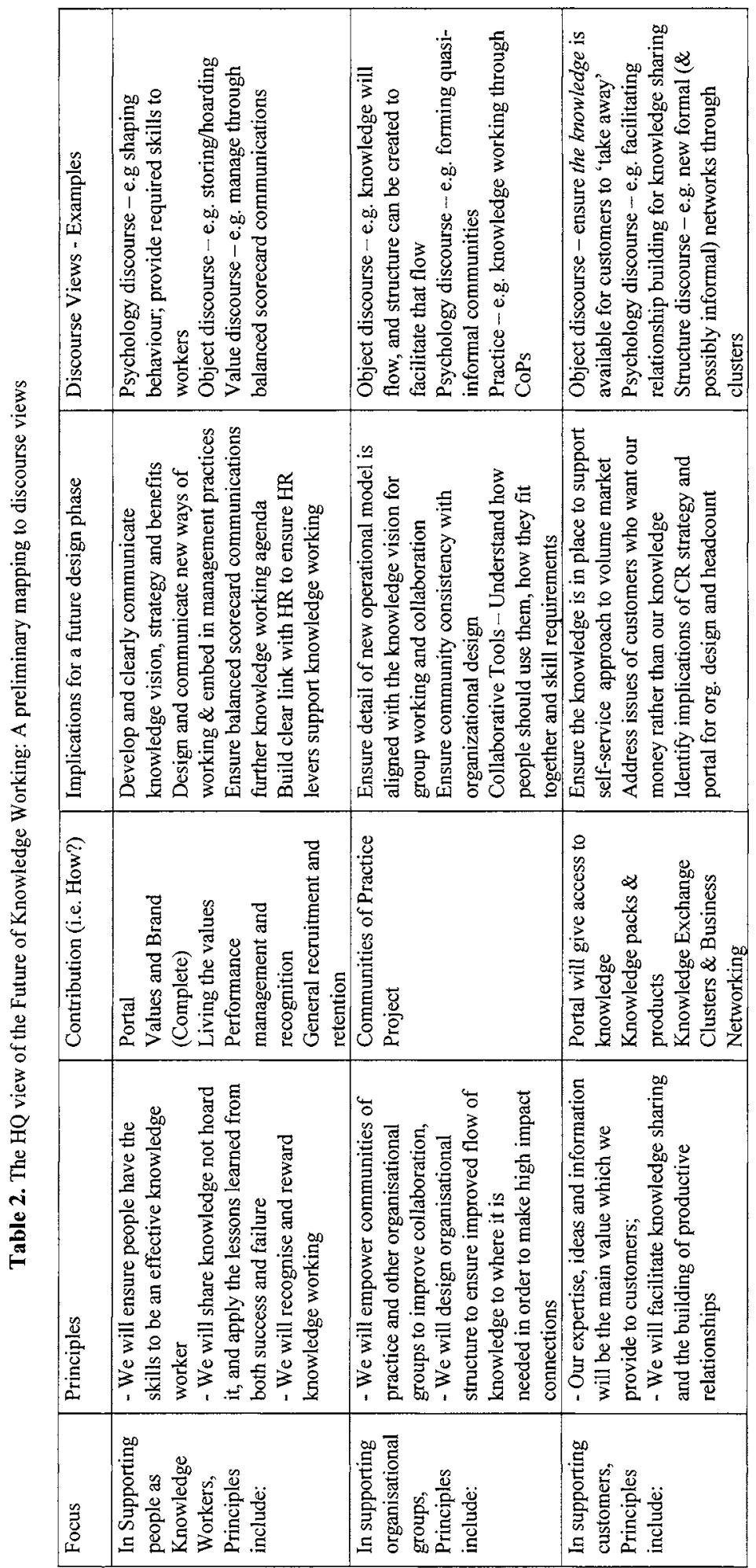

